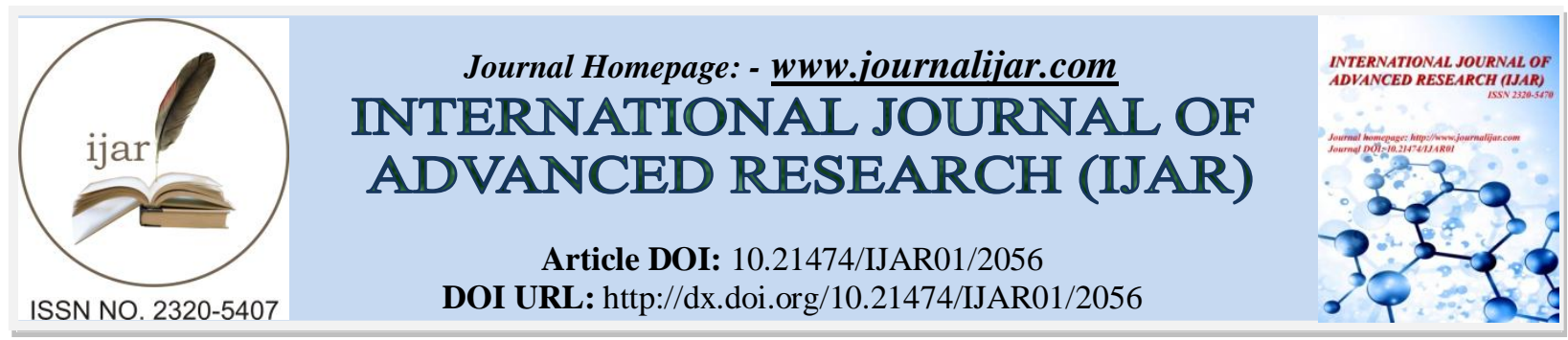

RESEARCH ARTICLE

\title{
PREDICTION OF NEPHROTOXICITY INDUCED BY CISPLATIN CHEMOTHERAPY IN CANCER PATIENTS.
}

Sherif Elzawawy, Eman Abo Shama, Anwar Mekhaeil and Fathy Abd Algawad. Clinical Oncology Department, Faculty of Medicine, Alexandria University, Egypt.

\section{Manuscript Info}

Manuscript History

Received: 20 September 2016

Final Accepted: 22 October 2016

Published: November 2016

Key words:-

Cisplatin, Prediction of nephrotoxicity.

\section{Abstract}

Background:- Cisplatin nephrotoxicity can present in a number of ways, the most serious is acute kidney injury which occurs in 20-30\% of patients. Other presentations include hypomagnesemia, distal renal tubular acidosis, hypocalcemia, renal salt wasting, renal concentrating defect, hyperuricemia, transient proteinuria, erythropoietin deficiency, thrombotic microangiopathy and chronic renal failure.

Objective:- To determine the incidence and risk factors for nephrotoxicity induced by cisplatin.

Methods:- Patients' files were retrospectively reviewed for demographic and clinical variables. Creatinine clearance was calculated using Cockcroft-Gault formula. Nephrotoxicity was defined as increase in creatinine level more than 1.5 times of baseline or decrease in creatinine clearance level more than $25 \%$ of baseline.

Results:- A total of 415 patients were recruited, with range of age 1686 years. 211 patients were males while 204 patients were females. There were 32 hypertensive patients, 49 diabetic patients and 108 smoker patients. $58.3 \%$ of patients had metastaic disease. The most frequent tumors were gastro intestinal, lung and breast cancers. 85 of the 415 patients $(20.5 \%)$ developed nephrotoxicity. Risk factors include age more than 60 years, diabetes mellitus, hypertension, cumulative dose $>450 \mathrm{mg} / \mathrm{m} 2$, anemia, combination chemotherapy regimens, and number of cycles more than 8 cycles, while gender, body mass index and smoking were not considered a significant risk factors for nephrotoxicity.

Conclusion:- Patients with risk factors for nephrotoxicity should be closely monitored, adequately hydrated, supplemented sufficiently with magnesium with avoidance of other nephrotoxic agents

Copy Right, IJAR, 2016,. All rights reserved.

\section{Introduction:-}

Cisplatin is one of the most commonly used antineoplastic agents for the treatment of solid tumors either as first or second line therapy. It is mainly used in treatment of carcinoma of urinary bladder, cervix, esophagus, gastric, ovarian, lung, head and neck tumors, germ cell tumor, lymphomas, mesothelioma and osteosarcoma. It can be also used as immunosuppressive and radio sensitizing agent. (1)

However, cisplatin has several side-effects such as nephrotoxicity, bone-marrow suppression, gastrointestinal toxicity, ototoxicity and neurotoxicity that limit its use. ${ }^{(2)}$ Cisplatin nephrotoxicity can present in a number of ways, 
the most serious and common presentation is acute kidney injury (AKI) which occurs in 20-30\% of patients. Other presentations include hypomagnesemia, Fanconi-like syndrome, distal renal tubular acidosis, hypocalcemia, renal salt wasting renal concentrating defect, hyperuricemia, transient proteinuria, erythropoietin deficiency, thrombotic microangiopathy and chronic renal failure. ${ }^{(3)}$

Cisplatin enters renal epithelial cells via the organic cation transporter (OCT2) and, to a lesser extent, Copper Transporter 1 (Ctr1) causing damage to nuclear and mitochondrial DNA and producing reactive oxygen species (ROS) which markedly increases the production of tumor necrosis factor $\alpha$ (TNF- $\alpha$ ) via phosphorylation of p38 mitogen-activated protein kinase (MAPK), leading to activation of both mitochondrial and non-mitochondrial pathways of apoptosis and necrosis of renal tubules. ${ }^{(4)}$

A decrease of $20 \%$ to $40 \%$ in glomerular filtration can be observed 10 days after intravenous infusion, followed by increased levels of creatinine and blood urea nitrogen, hypokalemia and hypomagnesemia (particularly after repeated doses of cisplatin). The urine output is usually preserved (non-oliguric) and the urine may contain glucose and small amounts of protein indicative of proximal tubular dysfunction. ${ }^{(5)}$

Glomerular filtration rate (GFR) is the most sensitive indicator of early cisplatin induced nephrotoxicity. It is a calculation that determines how well the blood is filtered by the kidneys, which is one way to measure remaining kidney function and also used to find the stage of chronic kidney disease. GFR is usually calculated using mathematical formulas that compare a person's weight, age, sex, and race to serum creatinine levels as Cockroft Gault, Jelliffe and Modification of Diet in Renal Disease (MDRD) formulas. GFR under $60 \mathrm{~mL} / \mathrm{min} / 1.73 \mathrm{~m}{ }^{2} \mathrm{may}$ mean kidney disease. It may not be a good measure of kidney health in some people, such as the very young or very old, amputees, or obese people. ${ }^{(6,7)}$

Recovery of renal function usually occurs over a period of 2-4 weeks. Progressive and permanent nephrotoxicity occurs more frequently with successive treatment courses and with increase in the cumulative dose of cisplatin. ${ }^{8,9)}$

In order to prevent and reduce patient risk of nephrotoxicity, screening for renal abnormalities, performing specific hydration procedures, osmotic diuresis, magnesium supplementations prior to drug administration, slower dose rate and modifying drug dosage (through decreasing, delaying or dividing it). Several dosing schedules exist and depend on aim of treatment whether curative or palliative, tumor type, stage, response, and concomitant therapy ${ }^{(10) .}$

Experimental strategies to reduce the risk of nephrotoxicity include reduced renal cisplatin accumulation or activation through administration of organic cation transporter (OCT2) inhibitors e.g., cimetidine or metformin, Ctr1 inhibitors, e.g., copper, liposomal cisplatin, Gamma-glutamyl transpeptidase inhibitors, Glutathione transferase inhibitors, or the use of antioxidant as Amifostine, N-acetyl cysteine, selenium or vitamin E. There are currently no unified recommendations for the treatment of nephrotoxicity. ${ }^{(11,12)}$

\section{Aim of the work:-}

This work aims to determine factors that increase risk of nephrotoxicity for patients treated with cisplatin either alone or in combination.

\section{Patients and Methods:-}

All patients' files who received cisplatin chemotherapy between January 2004 and January 2014 at Alexandria Main University Hospital were retrospectively reviewed.

Inclusion criteria: All age groups, all types of malignant tumors, at all stages, received more than two cycles of cisplatin, base line creatinine clearance more than $60 \mathrm{ml} / \mathrm{min}$, received either cisplatin alone or with combination .

Exclusion criteria: Patients with creatinine clearance equal or less than $60 \mathrm{ml} / \mathrm{min}$.

All cases were retrospectively reviewed for the following:

A. Age, gender, performance status and smoking habit.

B. Medical history: diabetes, hypertension, renal diseases and other systemic diseases affecting kidney, solitary kidney, and previous radiotherapy.

C. Laboratory investigations before each cycle of chemotherapy received including assessment of: blood urea, serum creatinine, glomerular filtration rate, serum albumin and hemoglobin. 
D. Treatment details: dose modifications, number of cycles of chemotherapy received, dose per cycle and cumulative dose of cisplatin and other nephrotoxic agents if present.

Nephrotoxicity was defined as an increase in serum creatinine level more than 1.5 times of baseline or decrease in creatinine clearance more than $25 \%$ of baseline.

\section{Statistical analysis of the data:-}

Data were fed to the computer using IBM SPSS software package version 20.0.

Qualitative data were described using number and percent. Comparison between different groups regarding categorical variables was tested using Chi-square test.

\section{Chi-Square test:-}

It tests the association between qualitative nominal variables; it is performed mainly on frequencies. It determines whether the observed frequencies differ significantly from expected frequencies.

$$
\text { Computed } X^{2}=\sum \frac{\left(\mathrm{O}_{\mathrm{i}}-\mathrm{E}_{\mathrm{i}}\right)^{2}}{\mathrm{E}_{\mathrm{i}}}
$$

Where $\mathrm{E}=$ expected frequency

$\mathrm{O}=$ observed frequency

$$
\mathrm{E}=\frac{\text { Raw total } \mathrm{x} \text { Column } \mathrm{t} \text { otal }}{\text { Grand total }}
$$

\section{Multi variant analysis:-}

Multivariate analysis (MVA) is based on the statistical principle of multivariate statistics wad done to determine the most significant risk factors which affected on the dependent variables.

\section{Results:-}

In this retrospective study, the medical files of 415 patients treated with cisplatin at Alexandria Main University Hospital were recruited from January 2004 to January 2014.The age ranged 16-86 years with a mean age 48 years. The creatinine level at the baseline ranged from 0.4 to 1.2 with a mean value of $0.822 \pm 0.406$ and the creatinine clearance ranged from 62 to 153 with a mean value of 107.3 45.3. Patient characteristics are summarized in table 1.

\begin{tabular}{|c|c|c|c|}
\hline \multicolumn{2}{|c|}{ Patient characteristics } & $\mathrm{N}($ total $=415)$ & $\%$ \\
\hline \multirow[t]{3}{*}{ Age } & $<40 \mathrm{y}$ & 94 & 22.6 \\
\hline & $40-60 y$ & 228 & 54.9 \\
\hline & $>60 y$ & 93 & 22.5 \\
\hline \multirow[t]{2}{*}{ Sex } & Male & 211 & 50.8 \\
\hline & Female & 204 & 49.2 \\
\hline \multirow[t]{3}{*}{ BMI } & $<25$ & 67 & 16.2 \\
\hline & $25-29.9$ & 240 & 57.8 \\
\hline & $\geq 30$ & 108 & 26.0 \\
\hline \multirow[t]{2}{*}{ Co morbidities } & Hypertension & 32 & 7.7 \\
\hline & DM & 49 & 11.8 \\
\hline Smoking & Yes & 108 & 26.0 \\
\hline \multirow[t]{6}{*}{ Tumor sites } & GIT & 102 & 24.5 \\
\hline & Bronchogenic carcinoma & 91 & 22.0 \\
\hline & Genitourinary system & 86 & 20.72 \\
\hline & Breast cancer & 62 & 14.9 \\
\hline & Soft tissue sarcoma & 20 & 4.82 \\
\hline & Carcinoma of unknown primary & 19 & 4.58 \\
\hline
\end{tabular}
Table 1:- Patient characteristics.. 


\begin{tabular}{|c|c|c|c|}
\hline & $\begin{array}{c}\text { Laryngeal cancer } \\
\text { Lymphomas } \\
\text { Hypopharyngeal cancer }\end{array}$ & $\begin{array}{c}16 \\
13 \\
6 \\
\end{array}$ & $\begin{array}{c}3.85 \\
3.1 \\
1.45 \\
\end{array}$ \\
\hline Cisplatin dose & $\begin{array}{l}<60 \mathrm{mg} / \mathrm{m} \\
>60 \mathrm{mg} / \mathrm{m}\end{array}$ & $\begin{array}{c}75 \\
340\end{array}$ & $\begin{array}{l}18.1 \\
81.9\end{array}$ \\
\hline Tumor stage & $\begin{array}{l}\text { II \& III } \\
\text { IV }\end{array}$ & $\begin{array}{l}173 \\
242\end{array}$ & $\begin{array}{l}41.7 \\
58.3\end{array}$ \\
\hline Previous chemotherapy & $\begin{array}{l}\text { first line } \\
\text { Second line }\end{array}$ & $\begin{array}{c}317 \\
98 \\
\end{array}$ & $\begin{array}{l}.76 .4 \\
23.6\end{array}$ \\
\hline Cisplatin & $\begin{array}{c}\text { Alone } \\
\text { Combination }\end{array}$ & $\begin{array}{c}92 \\
323 \\
\end{array}$ & $\begin{array}{l}22.2 \\
77.8\end{array}$ \\
\hline Cumulative dose & $\begin{array}{c}<300 \mathrm{mg} / \mathrm{m} 2 \\
300-450 \mathrm{mg} / \mathrm{m} 2 \\
450-600 \mathrm{mg} / \mathrm{m} 2 \\
>600 \mathrm{mg} / \mathrm{m} 2\end{array}$ & $\begin{array}{c}124 \\
85 \\
69 \\
137\end{array}$ & $\begin{array}{c}29.88 \\
20.48 \\
16.62 \\
33.0\end{array}$ \\
\hline No. of cycles & $\begin{array}{c}\text { up to } 6 \text { cycles } \\
8 \text { cycles } \\
10 \text { cycles } \\
12 \text { cycles } \\
\end{array}$ & $\begin{array}{c}190 \\
88 \\
112 \\
25 \\
\end{array}$ & $\begin{array}{c}45.8 \\
21.2 \\
27 \\
6 \\
\end{array}$ \\
\hline HB level & $\begin{array}{l}<10 \mathrm{gm} / \mathrm{dl} \\
>10 \mathrm{gm} / \mathrm{dl}\end{array}$ & $\begin{array}{l}124 \\
291\end{array}$ & $\begin{array}{l}29.9 \\
70.1\end{array}$ \\
\hline
\end{tabular}

85 of 415 patients (20.5\%) in the present study developed nephrotoxicity. Patients were divided into two groups: group of patients who developed nephrotoxicity and another one who did not develop nephrotoxicity. The two groups were compared in terms of, age, gender, BMI, diabetes mellitus, hypertension, smoking, anemia, cumulative dose of cisplatin, number of cycles, presence of previous chemotherapy and either cisplatin was given alone or in combination chemotherapy.

53/211 of male patients $(25.1 \%)$ had nephrotoxicity (decreased creatinine clearance more or equal than $25 \%$ of baseline creatinine clearance) compared to $32 / 204$ of female patients (15.7\%) had nephrotoxicity. The difference wasn't statistically significant $(\mathrm{P}=0.17)$.

Regarding age, 4/94 patients (4.25\%) who were aged less than 40 years developed nephrotoxicity during cisplatin treatment compared to $22 / 228$ patients $(9.6 \%)$ who are aged $40-60$ years and $59 / 93$ patients $(63.4 \%)$ who are aged $>60$ years, the differences were statistically significant $(\mathrm{P}=0.001)$. (Table 2)

Table 2:- Risk factors for nephrotoxicity.

\begin{tabular}{|c|c|c|c|c|}
\hline & & \multicolumn{2}{|c|}{ cisplatin nephrotoxicity } & \multirow[t]{2}{*}{$\mathrm{P}$ value } \\
\hline & & Yes $=85$ & $\mathrm{No}=330$ & \\
\hline & & $\mathrm{N}(\%)$ & $\mathrm{N}(\%)$ & \\
\hline \multirow[t]{3}{*}{ Age } & $<40 y$ & $4(4.3)$ & $90(95.7)$ & \multirow[t]{3}{*}{$0.0001 *$} \\
\hline & $40-60 y$ & $22(9.6)$ & $206(90.4)$ & \\
\hline & $>60 y$ & $59(63.4)$ & $34(36.6)$ & \\
\hline \multirow[t]{2}{*}{ Sex } & male & $53(25.1)$ & $158(74.9)$ & \multirow[t]{2}{*}{0.17} \\
\hline & female & $32(15.7)$ & $172(84.3)$ & \\
\hline \multirow[t]{3}{*}{ BMI } & $<25$ & $18(26.9)$ & $49(73.1)$ & \multirow[t]{3}{*}{0.18} \\
\hline & $25-29.9$ & $43(18)$ & $197(82)$ & \\
\hline & $\geq 30$ & $24(26)$ & $84(74)$ & \\
\hline \multirow[t]{2}{*}{ DM } & Yes & $37(75.5)$ & $12(24.5)$ & \multirow[t]{2}{*}{$0.0001 *$} \\
\hline & No & $48(13.1)$ & $318(86.9)$ & \\
\hline \multirow[t]{2}{*}{ Hypertension } & Yes & $20(62.5)$ & $12(37.5)$ & \multirow[t]{2}{*}{$0.0001 *$} \\
\hline & No & $65(17)$ & $318(83)$ & \\
\hline \multirow[t]{2}{*}{ Smoking } & Yes & $23(21.3)$ & $85(78.7)$ & \multirow[t]{2}{*}{0.083} \\
\hline & No & $62(20.2)$ & $245(79.8)$ & \\
\hline \multirow[t]{2}{*}{ Anemia } & Yes & $63(50.7)$ & $61(49.3)$ & \multirow[t]{2}{*}{$0.0001^{*}$} \\
\hline & No & $17(5.9)$ & $274(94.1)$ & \\
\hline
\end{tabular}




\begin{tabular}{|l|c|c|c|c|}
\hline Previous chemotherapy & Yes & $63(64.3)$ & $35(35.7)$ & \multirow{2}{*}{$0.0001^{*}$} \\
\cline { 2 - 4 } & No & $22(6.9)$ & $295(93.1)$ & \\
\hline chemotherapy & single & $2(2.2)$ & $90(97.8)$ & \multirow{2}{*}{$0.0003^{*}$} \\
\cline { 2 - 4 } & combination & $83(25.7)$ & $240(74.3)$ & \\
\hline \multirow{5}{*}{ Cumulative dose } & $<300 \mathrm{mg} / \mathrm{m}$ & $0(0)$ & $124(100)$ & \multirow{2}{*}{$0.0006^{*}$} \\
& $300-450 \mathrm{mg} / \mathrm{m}$ & $8(9.4)$ & $77(90.6)$ & \\
\cline { 2 - 4 } & $450-600 \mathrm{mg} / \mathrm{m}$ & $25(36.2)$ & $44(63.8)$ & \\
\cline { 2 - 4 } & $>600 \mathrm{mg} / \mathrm{m}$ & $52(37.9)$ & $85(62.1)$ & \\
\cline { 2 - 4 } & 4 cycles & $0(0)$ & $70(100)$ & \multirow{2}{*}{$0.001^{*}$} \\
\cline { 2 - 4 } & 6 cycles & $11(9.2)$ & $109(90.8)$ & \\
\cline { 2 - 4 } & 8 cycles & $18(20.5)$ & $70(79.5)$ & \\
\cline { 2 - 4 } & 10 cycles & $38(33.9)$ & $74(66.1)$ & \\
\cline { 2 - 4 } & 12 cycles & $18(72)$ & $7(28)$ & \\
\hline
\end{tabular}

For body mass index $(\mathrm{BMI})<25,26.9 \%$ patients developed nephrotoxicity compared to $18 \%$ patients for BMI between $25-29.9$ and $26 \%$ patients for $\mathrm{BMI} \geq 30$, the difference wasn't statistically significant $(\mathrm{P}=0.18)$. (Table 2 )

$37 / 49$ of diabetic patients (75.5\%) had nephrotoxicity compared to 48/366 of non diabetic patients (13.1\%) developed nephrotoxicity. The difference was statistically significant $(\mathrm{P}=0.0001)$. (Table 2$)$

20/32 of hypertensive patients (62.5\%) developed nephrotoxicity compared to $65 / 383$ of non hypertensive patients (17\%) showed nephrotoxicity, the difference was statistically significant $(\mathrm{P}=0.0001)$. (Table 2$)$

$20 / 108$ of smoker patients (21.3\%) developed nephrotoxicity compared to 62/307 non smoker patients (20.2\%) showed nephrotoxicity, the difference wasn't statistically significant $(\mathrm{P}=0.083)$. (Table 2$)$

63/124 of anemic patients (50.7\%) developed nephrotoxicity compared to 17/291 non anemic patients (5.9\%) had nephrotoxcicity, the difference was statistically significant $(\mathrm{P}=0.0001)$. (Table 2)

Regarding the cumulative dose of cisplatin, non of patients received cumulative dose $<300 \mathrm{mg} / \mathrm{m} 2(0 / 124)$ developed nephrotoxicity, $8 / 85$ patients $(9.4 \%)$ received dose $300-450 \mathrm{mg} / \mathrm{m} 2$ had nephrotoxicity, $25 / 69$ patients $(36.2 \%)$ received dose $>450-600 \mathrm{mg} / \mathrm{m} 2$ showed nephrotoxicity and $52 / 137$ patients $(37.9 \%)$ received dose > $600 \mathrm{mg} / \mathrm{m} 2$ developed nephrotoxicity, these differences were statistically significant $(\mathrm{P}=0.007)(\mathrm{P}=0.006)$. (Table 2)

Concerning the number of cycles, no patients (0/70) received 4 cycles developed nephrotoxicity $(0 \%), 11 / 120$ patients $(9.2 \%)$ who received 6 cycles had nephrotoxicity (increase serum creatinine $1.5-2.9$ times normal), 18/88 of patients $(20.5 \%)$ received 8 cycles showed nephrotoxicity (increase serum creatinine $1.5-2.9$ times normal), $38 / 112$ of patients $(33.9 \%)$ received 10 cycles developed nephrtoxicity (increase serum creatinine $1.5-2.9$ times normal) compared to $18 / 25$ patients $(72 \%)$ received 12 cycles had nephrotoxicity ( 12 patients increase serum creatinine $1.5-2.9$ times normal and 6 patients increase serum creatinine 3 times normal ). These differences were statistically significant $(\mathrm{P}=0.01)$. (Table 2$)$

$83 / 323$ of patients $(25.7 \%)$ received combination chemotherapy developed nephrotoxicity compared to 2/92 of patients $(2.2 \%)$ received single agent cisplatin. The difference was statistically significant $(\mathrm{P}=0.0003)$. (Table 2)

$63 / 98$ of patients $(64.3 \%)$ who received previous chemotherapy developed nephrotoxicity compared to $22 / 317$ of patients $(6.9 \%)$ who didn't receive previous chemotherapy, the difference was statistically significant $(\mathrm{P}=0.0001)$. (Table 2)

Mutivariate analysis showed that diabetic, hypertensive patients aged $>60$ years, who developed anemia during combination chemotherapy, or previously treated with chemotherapy, and with cumulative dose more than $450 \mathrm{mg}$ $/ \mathrm{m} 2$ or more than 8 cycles were at the highest risk for nephrotoxicity. 


\section{Discussion:-}

Nephrotoxicity of cisplatin is the most common restrictive factor for its clinical use in treating solid tumors. Approximately $25-40 \%$ of patients treated with cisplatin develop acute nephrotoxicity despite the adoption of conventional measures of hydration and osmotic dieresis, most are reversible. However, irreversible renal failure can occur when large doses are administered, or with repeated cycles of treatment.

The early stage of renal disorder generally does not cause symptoms. Functional impairment is only detected when creatinine clearence is less than $60 \mathrm{ml} / \mathrm{min}$. In this condition, renal impairment is more difficult to treat. Approximately $90 \%$ of renal function might be lost before clinical symptoms appear. Therefore, monitoring renal function (serum creatinine, creatinine clearance) is necessary to detect early renal impairment.

In this study, the incidence of nephrotoxicity due to cisplatin chemotherapy was $20.5 \%$ ( $85 / 415$ patients). Risk factors for nephrotoxicity include age $>60$ years, diabetes, hypertension, anemia, cumulative dose of cisplatin more than $450 \mathrm{mg} / \mathrm{m}$ and $\geq 8$ cycles of cisplatin. These results differ in comparison with other studies' results due to variation of the definition of nephrotoxicity from one study to another, variable cisplatin doses, and patient populations that differed by comorbidity and underlying malignancy ${ }^{(13)}$.

Marceau et al ${ }^{(14)}$, in their study of 118 patients treated with cisplatin therapy reported that $36.4 \%$ of patients developed nephrotoxicity, while Tiseo et al ${ }^{(15)}$, reported a lower nephrotoxicity with cisplatin with only 5 out of 107 patients $(4.7 \%)$ developed nephrotoxicity. Ries et al ${ }^{(16)}$ mentioned that a cisplatin dose from $50-75 \mathrm{mg} / \mathrm{m} 2$ is associated with reversible renal failure while a dose of $100 \mathrm{mg} / \mathrm{m} 2$ is associated with renal failure with tubular necrosis.

Prasaja et al ${ }^{(17)}$ published a trial in 2014 evaluating the incidence of cisplatin-induced nephrotoxicity and associated factors among cancer patients in Indonesia. Nephrotoxicity was defined as a decline of creatinine clearance to less than $60 \mathrm{ml} / \mathrm{min}$ using the Cockroft-Gault (CG) equation. 88 patients were included; nephrotoxicity occurred in 30 subjects $(34.1 \%)$ after four cycles and occurred in 29 subjects $(51.8 \%)$ after six cycles of cisplatin chemotherapy. Paired T-test showed a significant difference between creatinine clearance before and after 4 cycles of cisplatin $(\mathrm{n}=88, \mathrm{P}<0.05)$.

$51 \%$ of patients (17/33) aged equal or more than 50 years developed nephrotoxicity while $23.6 \%$ of patients (13/55) aged less than 50 years developed nephrotoxicity the difference was statistically significant $(\mathrm{P}=0.008) .35 .3 \%$ of female patients (18/51) had nephrotoxicity compared to $32.4 \%$ of male patients (12/37) developed nephrotoxicity, the difference was not statistically significant $(\mathrm{P}=0.78) .20 \%$ of diabetic patients $(1 / 5)$ developed decreased creatinine clearance below $60 \mathrm{ml} / \mathrm{min}$ compared to $34.9 \%$ of non diabetic patients (29/83) without statistically significant difference $(\mathrm{P}=0.567)$. 52\% of hypertensive patients $(13 / 25)$ developed decreased creatinine clearance below60 $\mathrm{ml} / \mathrm{min}$ compared to $27 \%$ of non hypertensive patients $(17 / 63)$, the difference was statistically significant $(\mathrm{P}=0.026) .34 .5 \%$ of patients received combination chemotherapy developed decreased creatinine clearance below $60 \mathrm{ml} / \mathrm{min}$.

Hyung et al ${ }^{(18)}$ retrospectively examined 552 patients who were diagnosed with gastric cancer, and received cisplatin combination chemotherapy between January 2002 and December 2008 at the Kosin University Gospel Hospital. Serum creatinine level of $1.5 \mathrm{mg} / \mathrm{dL}$ or more was used as the threshold for nephrotoxicity. $41 / 552$ patients (7.43\%) developed nephrotoxicity induced by cisplatin combination chemotherapy, these results probably underestimated the incidence of nephrotoxicity. In 41 patients, the average age was 58.36 years; the averages of the pre-nephrotoxic serum creatinine (SCR) and GFR were $1.21 \mathrm{mg} / \mathrm{dL} \pm 0.20 \mathrm{mg} / \mathrm{dL}$ and $66.29 \mathrm{mg} / \mathrm{mdL} \pm 12.74$ $\mathrm{mL} / \mathrm{min}$, respectively. Thus, their renal status prior to acute renal failure was already stage 2 according to the clinical guidelines published by the Working Group of the National Kidney Foundation (NKF). The most common cumulative dose of cisplatin at which nephrotoxicity occurred was $200-300 \mathrm{mg}$, while the second most common cumulative dose was 300-400 mg, and these were correlated with the greatest number of cycles and the dose of cisplatin per cycle.

Also, the results show that the patients who experienced a SCR $>1.75 \mathrm{mg} / \mathrm{dL}$ after receiving cisplatin combination chemotherapy had a greater risk of chronic renal failure than did patients with a SCR $<1.75 \mathrm{mg} / \mathrm{dL}$. Secondly, in subsequent chemotherapy regimens in patients who experienced SCR > $1.5 \mathrm{mg} / \mathrm{dL}$, the patients who continued cisplatin combination chemotherapy had a greater tendency to experience severe chronic renal disease. 
Therefore, these results suggest that when a patient experiences a SCR $>1.5 \mathrm{mg} / \mathrm{dL}$ after receiving cisplatin combination chemotherapy, the chemotherapy should be stopped, reduced, or the regimen should be changed, and when a patient experiences a SCR $>1.75 \mathrm{mg} / \mathrm{dL}$ after receiving cisplatin combination chemotherapy, the chemotherapy should be stopped or changed.

Older age and hypoalbuminemia are significantly associated with increased risk of cisplatin nephrotoxicity in most of the trials which was explained to be due to reduced number and volume of renal tubules, as well as increased synthesis of reactive oxygen compounds and inflammation in the ageing kidney. Also geriatric patients tend to have chronic kidney disease despite having no comorbidities. A high peak plasma concentration of free platinum is also associated with increased risk of nephrotoxicity. Low serum albumin concentration has also been reported as a significant risk factor for cisplatin-induced nephrotoxicity. Reduction in plasma albumin concentration might be associated with elevated free platinum concentration, leading to enhanced renal toxicity. ${ }^{(19)}$

Hypertension and diabetes mellitus increase the risk of nephrotoxicity significantly. The site of renal damage caused by cisplatin is different from that caused by hypertension and diabetes mellitus. Hypertension and diabetes mellitus destruct renal glomerulus while cisplatin causes destruction mainly in the renal proximal tubule. However, hypertension can cause ischemic glomerulosclerosis, which further stimulates interstitial fibrosis and tubular atrophy, the main target of cisplatin nephrotoxicity. ${ }^{(20,21)}$

Various urinary markers for early detection of AKI have been identified such as neutrophil gelatinase-associated lipocalin, urinary cystatin-c, $\mathrm{N}$-acetyl- $\beta$-glucosaminidase (NAG), microalbuminuria, $\alpha_{1}$-microglobulin $\left(\alpha_{1} M\right)$, Retinol binding protein (RBP), interleukin-18 and the kidney injury molecule-1. These biomarkers start to elevate soon in AKI (1-3 days before the increase in SCr), and do exhibit a great sensitivity and specificity in AKI diagnosis. ${ }^{(22,23)}$

Despite the recent physiopathological advances in the understanding of the mechanism of cisplatin nephrotoxicity, prevention still relies on decreases in drug dosage, hydration measures $1-2$ liters before and after treatment, 20 meq potassium chloride, $2 \mathrm{gm}$ magnesium sulphate and active screening for renal abnormalities. Mannitol is frequently used to induce diuresis, although there is no evidence that this is required. The addition of furosemide is generally not required, unless there is evidence of fluid overload. It is also recommend not using cisplatin in most patients with underlying renal disease; possible exceptions are situations in which cisplatin has a proven curative role, such as patients with testicular cancer. Also, co administration of other potentially nephrotoxic agents, such as aminoglycosides, non steroidal anti inflammatory agents, or iodinated contrast media should be avoided.

In conclusion, patients with risk factors for nephrotoxicity should be closely monitored during treatment, adequately hydrated, supplemented sufficiently with magnesium, use of platinum analogue if possible with avoidance of other nephrotoxic agents. Also, renal function should be evaluated using the GFR and should not use serum creatinine concentration as the sole mean for assessing the level of kidney function.

\section{References:-}

1. McEvoy GK, editor. AHFS (2004) Drug Information. Bethesda, Maryland: American Society of Health-System Pharmacists, Inc 22: 929-945.

2. Miller RP, Tadagavadi RK, Ramesh G, et al (2010). Mechanisms of cisplatin nephrotoxicity. Toxins, 2, 2490518.

3. Cullen, K.J.; Yang, Z.; Schumaker, L.; et al (2007). Mitochondria as a critical target of the chemotheraputic agent cisplatin in head and neck cancer. J. Bioenerg. Biomembr. 39, 43-50.

4. Yano T, Itoh Y, Matsuo M, et al (2007). Involvement of both tumor necrosis factor-alpha-induced necrosis and p53-mediated caspase-dependent apoptosis in nephrotoxicity of cisplatin. Apoptosis 12: 1901-1909.

5. Yao X, Panichpisal K, Kurtzman N, et al (2007). Cisplatin nephrotoxicity: a review. Am J Med Sci 334: 11524.

6. Israni AK and Kasiske BL (2011). Laboratory assessment of kidney disease: glomerular filtration rate, urinalysis, and proteinuria. In: Taal MW, Chertow GM, Marsden PA, et al., eds.Brenner and Rector's The Kidney. 9th ed. Philadelphia, Pa: Elsevier Saunders 25: 856-4.

7. Mitchell H, Rosner W (2006). Renal Function Testing, American journal of Kidney Diseases 47: 174-183.

8. Ma Q and Lu AY (2011). Pharmacogenetics, pharmacogenomics, and individualized medicine. Pharmacol Rev 63: 437-59. 
9. Gowda S, Desai P, Kulkarni S et al (2010). Markers of Renal function tests. North American Journal of Medical Sciences 2: 4-12.

10. Launay-Vacher V, Rey JB, Isnard-Bagnis C, et al (2008). Prevention of cisplatin nephrotoxicity: state of the art and recommendations from the European Society of Clinical Pharmacy Special Interest Group on Cancer Care. Cancer Chemother Pharmacol 61: 903-9.

11. Ciarimboli, G.; Deuster, D.; Knief, A.;et al (2010) . Organic cation transporter 2 mediates cisplatin-induced otoand nephrotoxicity and is a target for protective interventions. Am. J. Pathol.176, 1169-1180.

12. Pabla, N.; Murphy, R.F.; Liu, K.; Dong, Z (2009). The copper transporter Ctr1 contributes to cisplatin uptake by renal tubular cells during cisplatin nephrotoxicity. Am. J. Physiol. Renal Physiol.296, F505-F511.

13. Moon HH, Seo KW, Yoon KY, et al (2011). Prediction of nephrotoxicity induced by cisplatin combination chemotherapy in gastric cancer patients. World J Gastroenterol, 17, 3510-7.

14. Marceau D, Poirer M, Masson E, et al(1999) High Incidence of Nephrotoxicity with Cisplatin Therapy Despite Adequate Hydration: Risk Factors For Correlations. (Meeting Abstractg). American Society of Clinical Oncology Annual Meeting Abstract No. 840.

15. Tiseo M, Martelli O, Mancuso A, et al (2007). Short hydration regimen and nephrotoxicity of intermediate to high-dose cisplatin-based chemotherapy for outpatient treatment in lung cancer and mesothelioma. Tumori 93, 138-44.

16. Ries F, Klastersky J. (1986) Nephrotoxicity induced by cancer chemotherapy with special emphasis on cisplatin toxicity. AM J Kidney Dis 8: 368 - 79.

17. Yenny Prasaja,, Noorwati Sutandy, Retnosari Andrajati, (2014). Incidence of Cisplatin-Induced Nephrotoxicity and Associated Factors among Cancer Patients in Indonesia. Asian Pacifi Journal of Cancer Prevention, 250 (Vol 15): 22-31.

18. Hyung Hwan Moon, Kyung Won Seo, Ki Young Yoon, et al (2011) Prediction of nephrotoxicity induced by cisplatin combination chemotherapy in gastric cancer patients, Volume 17, Issue 30.

19. Nagai N, Kinoshita M, Ogata H, et al (1996). Relationship between pharmacokinetics of unchanged cisplatin and nephrotoxicity after intravenous infusions of cisplatin to cancer patients. Cancer Chemother Pharmacol 39: 131-137.

20. Corwin EJ. Hypertension (2008). Diabetes mellitus. In 'Handbook of Pathophysiology'. 3rd ed. Lippincott Williams and Wilkins, USA pp 430-34, 556-70.

21. Yao X, Panichpisal K, Kurtzman N, et al (2007). Cisplatin nephrotoxicity: a review. Am J Med Sci, 334, 11524.

22. Han WK, Bailly V, Abichandani R. (2002). Kidney injury molecule-1 (KIM-1): a novel biomarker for human renal proximal tubule injury. Kidney Int 62: 237-44.

23. Ichimura T, Hung C C, Yang S A, et al (2009). "Kidney injury molecule-1: a tissue and urinary biomarker for nephrotoxic cant-induced renal injury," American Journal of Physiology 286: 552-63. 